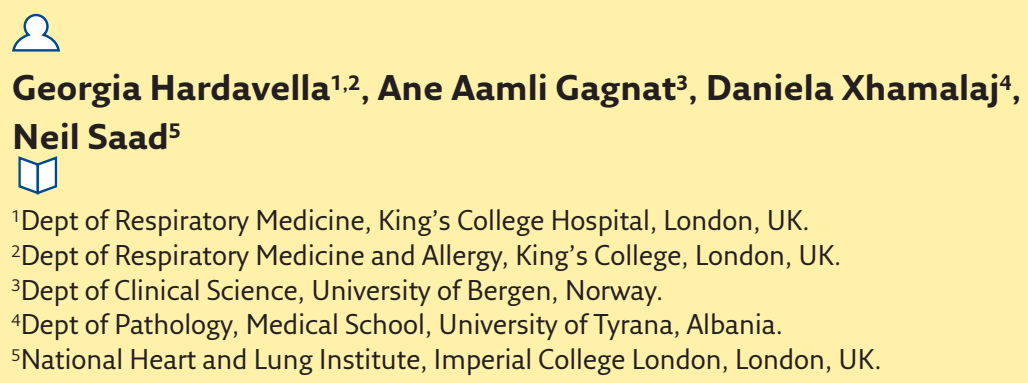

\title{
How to prepare for an interview
}

\section{Doing science}

"Combined with passion and perseverance, identifying and leveraging your strengths and aptitudes is the key to any career path."

Anadil Hossain

Upon receiving an invitation to an interview, you may feel as if you have finally gained your chance to prove yourself and then, in a few moments, this is almost always clouded by uncertainty, stress and "what if?" questions about your performance on the day: "What if they do not like me?", "What if I walk in there and I'm so stressed that I faint?", "What if the panel are aggressive?"

In this article, we will go through the preparation stages for an interview, highlight a few pitfalls to avoid and provide some guidance in promoting yourself on the day. Taking into account that readers will be at different stages in their careers, this article seeks to be generic yet applicable to various levels of clinical, research and industry positions.

Preparation for a job interview has always been challenging and, taking into account the diversity of undergraduate programmes in Europe, many early career members of the European Respiratory Society have not received dedicated training in interview techniques; therefore, we hope you will find this article helpful.

\section{What is an interview?}

You should consider an interview as the time to shine and to sell yourself in an efficient yet warm manner.

A job interview is essentially a meeting organised by a recruiter (academia, hospital, pharmaceutical company, etc.) that is used to evaluate a potential employee for prospective employment. However, consider this meeting as a two-way process between the candidate and the interviewer. The interviewer wants to find out how well the candidate could do the job and fit in with their organisation and team and the candidate aims to show that they are the best person for the job and for the organisation but they also should aim to find out more about the work environment.

Job interviews are usually face-to-face meetings; however, in recent years, telephone interviews and Skype interviews have become more commonplace. Interviews last approximately 45-60 mins, although telephone interviews may be slightly shorter.

Depending on the type of job you have applied for and seniority of the role, the interview panel may vary between three and 12 members. Usually, the more senior the job, the wider the composition of the panel.
Cite as: Hardavella G, Aamli Gagnat A, Xhamalaj D, et al. How to prepare for an interview. Breathe 2016; 12: e86-e90. 


\section{Before the interview}

In most cases, being invited to the interview usually means that you're qualified for the job; i.e. you meet all the essential criteria and most of the desirable ones (if not all of them). The interview is mostly about the panel finding out whether you can support what has been written on your application and how you can implement these things.

How you act in the interview and how you answer questions posed is crucial, regardless of whether you will get a job offer or not, and good preparation will give you a great advantage in presenting your personal skills. There are some simple steps to take before the interview to help you comfortably answer the interview questions and these are mainly focused on research and planning.

\section{Detective work}

The employer expects you to have knowledge about the organisation and the department you have applied for. We would recommend that you do a thorough search and read the organisation's website, social media profiles and key literature (e.g. business/research plan, clinical/research/ financial reports, recent accomplishments/awards/ fundings etc.). Also check the news, competitors, history and opportunities of the sector. Figure out which aspects they are focusing on, what is important to them and how they appear online? Then revisit the job description of the job you have been shortlisted for and place this into the bigger picture of the organisation.

Consider arranging a visit to the organisation to see the surroundings, talk to potential future colleagues and ask more about their processes. Get in touch with people who have worked at the institution or lab to find out more information. However, be cautious when talking to previous or current employees as they potentially may be biased by personal experiences.

Based on all this research, you need to think how your goals would match the organisation's goals and how your strengths and experience/expertise in the field will serve the organisation and/or even contribute to the solution of problems they may face. Knowing all this info shows enthusiasm for the job and also gives you the opportunity to apply your personal attributes to the organisation's needs and goals and establish a robust relationship right from the interview (or even before the interview if you have arranged a site visit). Some organisations have a dedicated section on their website with their values. Try to think of examples from your personal/professional life that reflect how you apply these values in daily life and be prepared to mention these during the interview.

However, bear in mind that the detective work is usually done reciprocally. Potential employers will usually do their research on you and even check your social media account. Therefore, you need to be mindful with regards to your internet presence.

\section{Review your CV and application form}

This translates into reviewing your skills, abilities and characteristics in detail and identifying those that apply to the potential future employer and job and also present them in a way that match their goals and needs. Imagine yourself in the actual position, what do you offer to the organisation? If you've reflected on this beforehand, it will make it easier to answer clearly and well during the interview. This gives an impression of good introspection. Try to remember relevant examples of applying similar skills in your previous job as it is always good to mention these during the interview.

It is of vital importance not to claim that you can do/know something that you do not. This is dishonest and it may ruin the whole interview process. Imagine that you state that you can speak fluent French and, during the interview, the panel decide to switch the interview language to French; this will be a very awkward moment!

A poorly chosen email address, used for communication purposes in the CV and application form, can reflect on your professionalism. Keep it simple and select a professional-looking email address e.g. lastname.firstname@...

\section{Contact your referees}

Your references would usually come from people that are really busy (former line manager, academics, etc.); therefore, it is essential that you alert them that you'll be interviewing and that they may receive a call or an email to which they need to respond promptly. Depending on the relationship you have with them, you might also ask them what their overall impression is about you. However, bear in mind that a good referee will always send you a copy of their reference unless it is in the form of an on-line questionnaire; in this case, they will update you. Some interviewers might ask you what your referees will say about you and knowing something about it, again, shows good introspection.

\section{Reverse thinking: think about the interview from the interviewer's point of view}

Inevitably you will need to do some brainstorming based on your detective work and introspection, during which you need to ask yourself the following questions:

- What are the employers looking for?

- How will they assess you?

- What questions are they most likely to ask to help them judge these things?

- How can you convince them that you are the best fit for the job and organisation?

- What evidence have you got to support that? 
Table 1 "Old time classic" questions that panellists are keen to ask

Can you talk to us through your CV?

Why did you choose this particular institution?

Why did you choose this job?

Why you? What skills/experience you have that would make you a good candidate?

What are your weaknesses/strengths?

How would you see yourself in 5 years' time?

This brings you to the point where you should anticipate potential questions and prepare answers accordingly in advance. Table 1 highlights the typical questions that you will be asked in most interviews.

\section{Can you talk to us through your CV?}

This is usually the first question that buys you a few minutes to talk and at the same time it will help you to feel more comfortable in the room. Start with a strong statement but be prepared to explain problematic aspects of your CV (e.g. career breaks, leaving a company, etc.). Concentrate on how your experience, successes or personal characteristics make you a strong candidate and avoid irrelevant information. The interview panel will probably be sitting there for a whole day, so aim to talk for a minute or so and include relevant information rather than chatter away, then check with the interviewers that they have enough information.

\section{Why did you choose this particular institution?}

As per your detective work, you can base your answers on the research you have done for the organisation. For example "This organisation has a high track record of setting up international randomised control trials in disease $X$ and acquiring successful European funding bids. There is a lot of support for early career researchers to set up their own groups and acquire funding, I know there are $\sim 10$ successful applications per year which is much more than what other well recognised European labs would get. In addition to that, you are the only lab in the region that performs the $\mathrm{Z}$ technique..."

\section{Why did you choose this job?}

This should be based on your detective work and CV preparation. Show the panel how the job will help you meet your professional goals and how they are compatible with the organisation's vision.

Why you? What skills/experience do you have that would make you a good candidate?

This is all about putting together what you think is special and relevant from your CV and showing the panel how well you fit the job description and person specification. As with the previous two questions, your preparation puts you in a strong position to give a strong answer.

\section{What are your weaknesses/strengths?}

This can be tricky depending on how you phrase things. When asked about your strengths, be honest but not arrogant. For example: "I see strengths in my background in being an efficient team player recognising equality and diversity within the team and achieving goals in a timely manner". When referring to your weakness, again be honest but try not to be such a harsh critic that you make yourself seem appalling. Additionally, answers such as "my greatest weakness is that I want to be perfect" are out of the question; these are risky clichés and should be avoided. Instead, think about something that isn't your strongest selling point and think how it has affected you in the past. Then show what actions you have taken to overcome it or to improve it and do not forget to mention that you are continuously working on this. For example "I used to feel uncomfortable when I started teaching medical students as part of my specialty training, mainly due to the lack of confidence in my presentation. To this effect, I undertook a teaching course that aimed to train trainers on how to organise their teaching and what teaching methods they could use to ensure their audience is engaged and absorbs information. After attending this, I have seen a significant improvement in the feedback I receive from students and I feel more confident when teaching them. I attend the refreshing course annually to ensure I continue to improve in teaching."

\section{How would you see yourself in 5 years' time?}

This is a question that aims to see your personal vision and needs to show indirectly how the advertised job in this specific organisation will help you get there. For example, if the advertised job is that of a chest physician with a special interest in asthma in a socioeconomically deprived area, your answer could be "I would see myself as a well-established chest physician having organised and coordinated a network of asthma community services extending to the most isolated parts of our province; therefore, ensuring healthcare access to patients from remote rural areas. In addition to that, I will have strengthened my bonds with the local university to develop clinical trials in asthma with main focus on tackling socioeconomical inequalities in the management of asthma."

\section{Practise}

Practise with your mentor or an experienced friend. They should pretend they are the interviewer. After you are finished, request their feedback; 
what was done particularly well, what could have been done differently, whether there was anything you should change or leave out. In big institutions, "mock interviews" are often offered to candidates that have planned to move on and have applied for new jobs. Should this be the case with your institution, then this is definitely something you can benefit from. If your mentor or friend is not available and mock interviews are not offered by your institution, then you can practise in front of a mirror or, even better, film yourself! The latter can be of real benefit as it picks up elements that you may have not even considered and can help you identify potential weak points that you can work on and improve.

\section{Dress to impress}

The first impression matters more than you would want and it is the visual expression that is first notable. Therefore choosing the right clothing is necessary. Everything from hair to toes should be clean and presentable. Focus on personal hygiene, shower right before the interview, have a clean shave and dress up nicely. Different organisations have different dress codes, so if you are uncertain, calling the central switch board beforehand is a good idea. Traditionally, this would be smart business attire, but if you are in any doubt, overdress rather than underdress. Often a good choice is a professional look that you are comfortable with. You do not want to be the person that turns cyanotic in front of the panel as the shirt collar is too tight! If you feel misplaced in your own clothing, it will easily show.

Avoid alcohol consumption the night before and get plenty of sleep. In addition to the visual impression, make sure to plan your journey in advance, collect all the necessary documents to have them ready on the day, and arrive 15 mins earlier than the interview time.

\section{During the interview}

When entering the interview room, try to be relaxed, have a confident smile and make eye contact. When meeting the panel, introduce yourself with a handshake. If the panel is comprised of more than three members, then this may not be feasible and is not recommended. Instead, introduce yourself by making eye-contact with all panel members.

\section{Body language and direct eye contact are key}

Maintain a positive body language throughout the interview, speak clearly and in full sentences, smile frequently and make eye contact. During questioning, sit upright, listen to the questions and try to answer as clearly and concisely as possible. Also maintain good manners with any staff member or interviewers that you might meet before or after the interview, or even during the coffee break, lunch or dinner. Don't forget that while you are with any of the institution's or company's staff, you are being assessed, whether the setting is formal or informal.

\section{Use examples}

"Tell us about yourself". Whether it is the first question or another similar one, use it as a moment to shine by giving examples how you achieved positive outcomes and what your contribution was. Don't forget to use "I" rather than "we" and highlight why you are the one they should hire.

\section{Be prepared for an interviewer that will try to put you off by their questioning}

It rarely happens but the interviewer(s) may try to see how you respond under pressure by employing an aggressive line of questioning, or ask incoherent or non-sensible questions or questions that betray a lack of understanding in the topic. Don't ever let your temper get the better of you and make sure you remain calm and polite.

\section{Never badmouth any previous employers}

Even if you have had enough with your previous job, you should never badmouth a former employer in an interview. If specifically asked (this may come as "why did you leave your last job?") try to keep your tone somewhere between neutral and positive and try to emphasise on what you've learned in that job and what you're hoping to do in the future which will blend nicely with the new job you have applied for. On a similar note, do not talk negatively or disrespectfully about any person that you have worked for/with in the past. This is disliked by panellists and it may give the impression that you were the cause of the conflict or problematic relationship.

\section{Avoid talking about personal problems}

This is not the time and place to bring up issues you may have with your ex-wife or children or any other family issues that affect your personal life. You are strongly advised to leave these outside the interview room.

\section{Avoid using buzzwords or jargon}

These words may mean nothing and if overused they will almost certainly create a negative impression to 
the panel so try to avoid them. Instead try to bring your enthusiasm for the job across.

\section{Ask questions at the end}

In the end you will be asked if you have any questions. Therefore, you should prepare some questions about the job, workplace, institution and personal development on the job. Even if the panel has covered most of what you wanted to know, ask a question that is relevant and thought-provoking. This can show that you're genuinely interested in the role and really listening to the panel. To not ask a question may make you come across as disinterested.

\section{After the interview}

After the interview, there is a seemingly endless time that you are waiting for the result. In the worst case scenario that your interview was an unpleasant experience, it is generally better not to openly complain about it to your professional circle or start making calls or sending e-mails.

Regardless of whether you get the job or not, it is important to take notes (now that your memory is still fresh) and try to remember the questions and your responses to them. Focus on what you think went really well and what could have been said in a different way. You should reflect on what could have been done differently and how this can be achieved in the future. This brief self-evaluation gives you a better insight of your performance and will help you improve for future interviews.

Seeking feedback from the interview panel is very helpful as it may provide you with valuable information that you might not have picked up in your self-evaluation. In the case you have got the job you can request the feedback informally over a friendly cup of coffee/tea with your panellists after you have started working in the organisation. If you did not get the job, we recommend that you send a "thank you" e-mail to the panel and a kind request for feedback as this will give you a better insight and will help you work further on your interview skills. This should be sent within 24-48 h. Remember, try to use this feedback constructively and do not see it as a reason to argue with the hiring manager.

Usually the majority of employers will get back to you within 24-48 h to let you know whether you have been successful or not. In the rare case that a response takes weeks or months, you should not stop attending further interviews for other promising jobs. It is a free market and you should always keep your options open.

\section{Conflict of interest}

None declared.

\section{Further reading}

1. Olivier Picard, Dan Wood, Sebastian Yuen, eds. Medical Interviews (2nd Edition): A comprehensive guide to CT, ST \& Registrar Interview Skills. 2nd Edn. London, ISC Medical, 2013.

2. Robert Ghosh. Succeeding in Your Consultant Medical Interview: A comprehensive guide to interview question topics and NHS issues. London, BPP Learning Media, 2012.

3. 7 Essential Skype Interview Tips. Available from www. topuniversities.com/blog/7-essential-skype-interview-tips Date last accessed: July 10, 2016.
4. Chris Smith, Darryl Meeking, eds. How to Succeed at the Medical Interview. Hoboken, Willey Blackwell Publishers, 2013.

5. Julie Gray. Interview Success: Get the Edge: A Teach Yourself Guide. Teach Yourself. New York, McGraw-Hill editions, 2012.

6. Philip Charsley. Interview Preparation: Deconstructing the Interview Process. CreateSpace Independent Publishing Platform, 2014. 